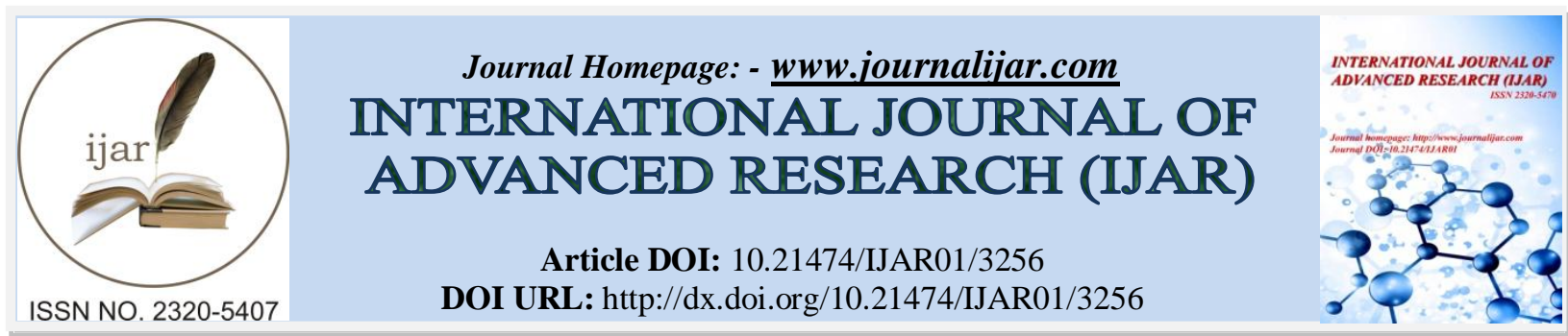

RESEARCH ARTICLE

\title{
JUVENILE MYOCLONIC EPILEPSY AND MIGRAINE: STUDY OF COMORBIDITY AND CLINICAL CO-OCCURRENCE.
}

Saleh Atteya, Ahmed Azab, Farha El-chennawi, Ebrahem Elmenshawi and Mohammed Abbas.

\section{Manuscript Info}

Manuscript History

Received: 27 December 2016

Final Accepted: 28 January 2017

Published: February 2017

\begin{abstract}
Epilepsy and migraine are comorbid with each other as they have common pathophysiological and electrophysiological phenomena. Materials and methods: Patients with Juvenile myoclonic epilepsy(JME) diagnosed by clinical and electrophysiological study (electroencephalogram) with or without comorbid migraine underwent detailed history for migraine headache, general examination, neurological examination and brainMRI and MRS.

Results: Migraine was clinically associated with JME in 58.6\% of cases. NAA/CR and $\mathrm{CHO} / \mathrm{CR}$ ratio were significant $(\mathrm{P}<0.05)$ between JME cases and control group and non-significant between JME cases with or without migraine $(\mathrm{P}>0.05)$.

Conclusion: migraine is highly comorbid with JME risk factors are female gender and family history of migraine, with no structural or functional comorbidity in MRS study
\end{abstract}

Copy Right, IJAR, 2017,. All rights reserved.

\section{Introduction:-}

Migraine and epilepsy are highly comorbid disorders and share clinical features that suggest overlapping, pathophysiological and etiological conditions with episodic manifestations (1)

Both migraine and epilepsy represent distinct families of neurological disorders with typical constellations of symptoms (2)

Juvenile myoclonic epilepsy is a common epileptic syndrome, the etiology of which is genetically determined. Its onset occurs from 6 through 22 years of age, and affected patients present with myoclonic jerks, often associated with generalized tonic-clonic seizures (the most common association) and absence seizures. (3)

Migraine and epilepsy are often comorbid. Risk factors are positive family history and female gender or triggers as (alcohol, menses, and irregularity of sleep) as well as prophylactic drugs (valproate, topiramate) are shared by both. This suggests that migraine and epilepsy may have some common pathophysiological mechanisms (4). Proposed mechanisms include an increased excitability of the cortex accounting for the increased risk of migraine and epilepsy or seizures being triggered by migraine attacks, as the term migralepsy of the International Classification of Headache Disorders (2004) (ICHDII) suggests. It is well known that seizures can trigger secondary headache attacks as postictal headache $(5,6)$ 


\section{Material and Methods:-}

The study was conducted on 41 Egyptian patients at Mansoura University Hospital ,divided into two groups. The first group was 29 patients JME cases with or without comorbid migraine. And the second group was 12 control cases (normal cases who are not epileptic or suffer from migraine with no family history of epilepsy with normal conventional MRI brain).with the following Inclusion criteria: JME cases definitely diagnosed by clinical and electrophysiological studies with or without migraine with no age specific for JME patients and Informed consent.

\section{Methodology:-}

All patients diagnosed will be subjected to the following(1)Detailed history : The following history items will be considered in assessment of comorbidity and exclusion of other causes of epilepsy and assessment of the type of migraine (if it is present).

$>$ Age, sex personal history of the patient.

$>$ Age of onset of seizers.

$>$ The presence of migraine and its temporal profile, diagnostic criteria, type (common, classic or complicated).

$\triangleright$ A careful family history with attention to epilepsy, consanguinity, migraine.

General examination and Full neurological examination.

sleep deprivation Electroencephalogram EEG including both hyperventilation and photic stimulation.

Radiological examination: including (a)Conventional MR imaging:

Imaging were reviewed to exclude other pathologic processes. (b)1H-MRS :Cho, Cr were calculated. The ratios of integrals of various metabolites calculated with respect to $\mathrm{Cr}$ included, $\mathrm{Cho} / \mathrm{Cr}$ and $\mathrm{NAA} / \mathrm{Cr}$.

\section{Data analysis:-}

$>$ Data were entered and statistically analyzed using the Statistical Package for Social Sciences (SPSS) version 20.

$>$ Qualitative data were described as numbers and percentages. $\chi 2$ test and Fischer exact test were used for comparison between groups, as appropriate.

$>$ Quantitative data were described as means (SD) or medians, as appropriate. They were tested for normality by Kolmogorov-Smirnov test. In the normally distributed variables, one way ANOVA test and Student $t$ test were used for comparison between groups; Spearman correlation was used for parametric quantitive and ordinal variables correlation.

$>$ "p value $\leq 0.05$ " was considered to be statistically significant and $<0.01$ high statistically significant.

\section{Results:-}

The study was conducted on $29 \mathrm{JME}$ cases $16(55.1 \%)$ male patients and 13(44.9\%) female patients with median age $21.4 \pm 8.1$ with non significant difference between $\mathrm{p}>.05$ (table 1).

17 (58\%) patients were comorbid with migraine 6(35.3\%) male and 11(64.7\%) female with median age $23.12 \pm 7.03 .12(42 \%)$ patients were not comorbid with migraine, $10(83.3 \%)$ male and $2(16.7 \%)$ female with median age 19.25 \pm 5.92 (table 2).

The median age for the onset of migraine in the studied group was $14.12 \pm 4.9$, median duration of migraine attacks was 12.0(4.0-48.0), for the onset of the symptoms of JME (myoclonic jerks) was 10.66 \pm 2.6 , the onset of absence seizures was $11.4 \pm 2.7$ while the onset of GTCs was 18.72 \pm 3 .9.(table 3).

In JME cases with migraine $12(70.6 \%)$ cases were common migraine, while $5(29.4 \%)$ cases were classic migraine, and as regard time of migraine in relation to seizures one (5.8\%) patient showed migraine attacks post ictal, 2 patients $(11.6 \%)$ pre ictal and 14 patients $(82.6 \%)$ showed migraine attacks not related to seizures. In this studied group $10(58.8 \%$ ) of cases showed positive family history of migraine (Table 4).

From logistic regression analysis it shows that in JME cases female and patient with frequent GTCS are of high risk to develop migraine (table 5) 
MRS study showed that there was statistically significant difference ( $\mathrm{p}<0.05)$ in NAA/CR and $\mathrm{CH} / \mathrm{Cr}$ ration in both frontal lobe and thalamus between patients and control group and no statistically significant difference in NAA/CR and $\mathrm{CH} / \mathrm{Cr}$ ration in both frontal lobe and thalamus between JME cases with migraine and JME cases without migraine (table 6,7)

Table 1:- Demographic characters of studied groups

\begin{tabular}{|l|l|l|l|}
\hline & $\begin{array}{l}\text { JME cases } \\
\mathbf{n = 2 9}\end{array}$ & $\begin{array}{l}\text { Control } \\
\mathbf{n = 1 2}\end{array}$ & Significance \\
\hline Age & & & \\
\hline Mean \pm SD & $21.4 \pm 8.1$ & $27.75 \pm 9.39$ & $\mathrm{~F}=1.329$ \\
$($ Min-Max) & $(8.0-40.0)$ & $(19.0-40.0)$ & $\mathrm{P}=0.28$ \\
\hline Sex & $\mathrm{n}(\%)$ & $\mathrm{n}(\%)$ & \\
\hline$\square \quad$ Male & $16(55.1)$ & $5(41.7)$ & $\begin{array}{l}\chi^{2}=2.263 \\
\mathrm{p}=0.323\end{array}$ \\
\hline Female & $13(44.9)$ & $7(58.3)$ & \\
\hline
\end{tabular}

F: One Way ANOVA test $\quad \chi^{2}=$ Chi square test

Table 2:- Demographic data of JME cases

\begin{tabular}{|l|l|l|l|}
\hline & $\begin{array}{l}\text { Cases without migraine } \\
\mathbf{n = 1 2}\end{array}$ & $\begin{array}{l}\text { Cases with migraine } \\
\mathbf{n}=\mathbf{1 7}\end{array}$ & $\begin{array}{l}\text { Test } \\
\text { significance }\end{array}$ \\
\hline Age & $19.25 \pm 5.92$ & $23.12 \pm 7.03$ & $\begin{array}{l}\mathrm{t}=1.55 \\
\mathrm{p}=0.132\end{array}$ \\
\hline Sex & & & \\
\hline Male & $10(83.3)$ & $6(35.3)$ & $\chi^{2}=6.56$ \\
$\mathrm{p}=0.01^{*}$
\end{tabular}

Table 3:- age of onset of JME and migraine and duration of migraine attacks

\begin{tabular}{|l|l|}
\hline $\begin{array}{l}\text { Migraine onset } \\
\text { Mean } \pm \text { SD(min-max) }\end{array}$ & $14.12 \pm 4.9(8.0-26.0)$ \\
\hline $\begin{array}{l}\text { Migraine Duration (hours) } \\
\text { Median(min-max) }\end{array}$ & $12.0(4.0-48.0)$ \\
\hline $\begin{array}{l}\text { Age of absence } \\
\text { Mean } \pm \text { SD }\end{array}$ & $11.4 \pm 2.7$ \\
\hline $\begin{array}{l}\text { Age of myoclonus } \\
\text { Mean } \pm \text { SD }\end{array}$ & $10.93 \pm 2.9$ \\
\hline $\begin{array}{l}\text { Age of GTC } \\
\text { Mean } \pm \text { SD }\end{array}$ & $18.72 \pm 3.9$ \\
\hline $\begin{array}{l}\text { Age of onset of symptoms } \\
\text { Mean } \pm \text { SD }\end{array}$ & $10.66 \pm 2.6$ \\
\hline
\end{tabular}

Table 4 :- Migraine characters in studied cases

\begin{tabular}{|c|l|l|}
\hline Classic /Common migraine & $\mathbf{n = 1 7}$ & \% \\
\hline$\square \quad$ Common & & \\
\hline$\square \quad$ Classic & 12 & 70.6 \\
\hline Relation to seizure & 5 & 29.4 \\
\hline$\square \quad$ Pre ictal & & \\
\hline$\square \quad$ post ictal & 1 & 11.6 \\
\hline$\square \quad$ non related & 2 & 5.8 \\
\hline Family hx of migraine & 15 & 82.6 \\
\hline & & \\
\hline
\end{tabular}


Table 5:- Logistic regression in prediction of migraine

\begin{tabular}{|c|l|l|l|l|l|}
\hline Predictors & $\beta$ & P value & Odds ratio & \multicolumn{2}{l|}{$95.0 \%$ C.I. } \\
\hline Sex & & & & Lower & Upper \\
\hline$\quad$ Male(r) & & & & & \\
\hline$\quad$ Female & 2.566 & $0.017^{*}$ & 13.02 & 1.58 & 106.96 \\
\hline frequent symptom & & & & & \\
\hline$\quad$ GTC (r) & & & & & \\
\hline$\square \quad$ Myoclonus & -2.352 & $0.031^{*}$ & 0.095 & .011 & .802 \\
\hline $\begin{array}{l}\text { Model } \chi^{2}=\mathbf{1 2 . 8 4} \\
\text { percent predicted=79.3\% }\end{array} \quad \mathbf{0 . 0 0 2 * *}$ Constant=3.408 \\
\hline
\end{tabular}

Table 6:- $\mathrm{Ch} / \mathrm{Cr}$ and NAA/Cr of frontal and thalamic regions of patients and control

\begin{tabular}{|l|l|l|l|l|l|}
\hline & & $\begin{array}{l}\text { Patients } \\
\mathbf{n = 2 9}\end{array}$ & $\begin{array}{l}\text { Control } \\
\mathbf{n = 1 2}\end{array}$ & t test & p value \\
\hline \multirow{5}{*}{ Frontal } & $\mathrm{NAA} / \mathrm{Cr}$ & $1.48 \pm 0.195$ & $1.88 \pm 0.32$ & 4.84 & $<0.001^{* *}$ \\
& & $(1.19-2.1)$ & $(1.43-2.34)$ & & \\
\cline { 2 - 6 } & $\mathrm{Ch} / \mathrm{Cr}$ & $1.17 \pm 0.19$ & $1.008 \pm 0.25$ & 2.41 & $0.021^{*}$ \\
& & $(0.79-1.67)$ & $(0.78-1.59)$ & & \\
\hline Thalamic & $\mathrm{NAA} / \mathrm{Cr}$ & $1.526 \pm 0.29$ & $2.304 \pm 0.32$ & 7.58 & $<0.001^{* *}$ \\
& & $(1.08-1.98)$ & $(1.75-2.66)$ & & \\
\cline { 2 - 7 } & $\mathrm{Ch} / \mathrm{Cr}$ & $1.27 \pm 0.204$ & $1.067 \pm 0.122$ & 3.137 & $0.003^{* *}$ \\
& & $(0.93-1.76)$ & $(0.93-1.24)$ & & \\
\hline
\end{tabular}

Table 7:- $\mathrm{Ch} / \mathrm{Cr}$ and NAA/Cr of frontal and thalamic regions of patients with and without migraine.

\begin{tabular}{|c|c|c|c|c|c|}
\hline & & $\begin{array}{l}\text { patients without migraine } \\
\mathrm{n}=12\end{array}$ & $\begin{array}{l}\text { patients } \\
\text { migraine } \\
n=17\end{array}$ & t test & $p$ value \\
\hline \multirow[t]{2}{*}{ Frontal } & $\mathrm{NAA} / \mathrm{Cr}$ & $\begin{array}{l}1.473 \pm 0.114 \\
(1.29-1.67)\end{array}$ & $\begin{array}{l}1.487 \pm 0.24 \\
(1.19-2.1)\end{array}$ & 0.202 & 0.841 \\
\hline & $\mathrm{Ch} / \mathrm{Cr}$ & $\begin{array}{l}1.188 \pm 0.177 \\
(0.92-1.58) \\
\end{array}$ & $\begin{array}{l}1.174 \pm 0.203(0.79- \\
1.67)\end{array}$ & 0.184 & 0.855 \\
\hline \multirow[t]{2}{*}{ Thalamic } & $\mathrm{NAA} / \mathrm{Cr}$ & $\begin{array}{l}1.542 \pm 0.32 \\
(1.12-1.98)\end{array}$ & $\begin{array}{l}1.515 \pm 0.28 \\
(1.08-1.98) \\
\end{array}$ & 0.24 & 0.812 \\
\hline & $\mathrm{Ch} / \mathrm{Cr}$ & $\begin{array}{l}1.248 \pm 0.189 \\
(0.96-1.58)\end{array}$ & $\begin{array}{l}1.28 \pm 0.22 \\
(0.93-1.76)\end{array}$ & 0.404 & 0.689 \\
\hline
\end{tabular}

\section{Discussion:-}

Juvenile myoclonic epilepsy is a well-defined type of idiopathic generalized epilepsy that comprises $5-11 \%$ of patients with epilepsy; it is characterized by myoclonic jerks and generalized tonic colonic seizures (GTCS) and typical findings of generalized $4-6 \mathrm{~Hz}$ spike and wave or polyspike and wave discharges on electroencephalography (EEG) (7)

Migraine is a primary headache disorder characterized by recurrent headaches that are moderate to severe. Typically, the headaches affects one half of the head, are pulsating in nature, and lasts from two to seventy two hours. Associated symptoms may include nausea, vomiting, and sensitivity to light, sound, or smell (8).

Migraine and epilepsy are two chronic disorders characterized by repeated attacks of neurological dysfunction and are mostly accompanied by gastrointestinal, autonomic and other pathophysiological disorders. Migraine and epilepsy are linked by their symptom profiles, comorbidity and treatment. A person suffering from one of these diseases is twice as at risk of having the other one $(9,10)$.

The association of epilepsy and migraine indicates comorbidity which does not occur by accident, according to epidemiological studies. The reasons are partly genetic $(11,12)$, but at the same time both disorders exhibit common 
pathophysiological and electrophysiological phenomena. These two disorders also exhibit comparable clinical phenomena which may lead to confusion (13).

In our study we tried to find the comorbidity both clinically and functionally (through MRS) between specific type of idiopathic generalized epilepsy which is juvenile myoclonic epilepsy and migraine.

The myoclonic jerks were a core feature for diagnosis of JME present in all cases (100\%) diagnosed as JME, and GTCs were also present in all cases (100\%) in comparison to a general incidence of about (80-90\%) in JME patients and about $17 \%$ of patients show typical simple absence seizures, with the general incidence of absence seizures in JME patients $20-30 \%$ (14).

Our study had demonstrated a clinical co-morbidity between JME and migraine in about 17 cases of the studied sample (58\%) compared to a general incidence of association between epilepsy and migraine about 15-24\% (15) while the maximum incidence of association between epilepsy and migraine described by Syvertsen et al(16) was $52 \%$. While the incidence of clinical comorbidity between migraine and JME was estimated to be $36-41 \%$ (17, 18, 19). The slight higher incidence in our study may be attributed to the small sample size.

Female gender of JME patients who are comorbid migraine was higher than male gender $(65 \%$ female and $35 \%$ male) which is matched with other studies done on either JME and migraine or done on epilepsy in common and migraine(17,20). And this is can be attributed to the general common incidence of migraine in female (21).

Ito et al(22)had investigated the post ictal migraine attacks that occur immediately after the attacks of epilepsy and found a prevalence of about $4.25 \%$ of cases of comorbid epilepsy and migraine which is matched to our results which postulates that about $6 \%$ of JME patients experienced immediate post ictal migraine and also the same result was described in other studies that investigated the actual timing of occurrence of migraine attacks in epileptic patients and the relation of the migraine attack to the epileptic seizure (23,24).

Since both JME and migraine are highly linked to genetic and hereditary basis, in our study positive family history of migraine was found to a higher incidence in JME cases with migraine $60 \%$ compared to only $25 \%$ positive family history of migraine JME cases with migraine which supports a strong genetic background(25).

Elmassry et al,(26) had postulated that migraine onset was more likely to have occurred 1-3 years after the onset of epileptic attacks in comorbid cases, and it is concomitant with our study as the age of onset of JME (the onset of myoclonic jerks) was about 10.5 years with the age of onset of migraine attacks about 14 years.

On summarizing the MRS finding in our JME patients in relation to control group we found significant decrease in the frontal and thalamic NAA concentration and NAA/Cr ratio in JME cases than control group. These findings are concomitant with the finding of meta-analysis by Anderson, $J$ and Hamandi, $K(27)$. These results are also coincident with the findings of other studies, including behavioral and neuropsychological studies that revealed that patients with JME were similar to those with frontal lobe epilepsy upon impairment $(28,29)$.

In our study there was no significant difference in MRS findings both in frontal lobe and thalamus in JME cases with or without migraine (either common or classic). These findings are supported by the fact that in migraine MRS findings show only a reduction in NAA in the occipital cortex in migraine with aura (classic migraine) before and after visual stimulation with normal NAA level in between the attacks compared to normal NAA level in migraine without aura and control group (30).

\section{Conclusion:-}

On summarizing our findings there is a well-established clinical correlation between JME and migraine, which may be attributed to sharing the same pathophysiological aspects or sharing common genetic background, but unfortunately this common clinical association cannot be confirmed objectively by using functional MRS modalities which gives no added information when JME is comorbid with migraine than JME cases only. 


\section{References:-}

1. Lyngberg AC, Rasmussen BK, Jorgensen T, Jensen R. Incidence of primary headache: a Danish epidemiologic follow-up study. Am J Epidemiol 2005; 161: 1066-73.

2. Koch UR, Musshoff U, Pannek HW, et al. Intrinsic excitability, synaptic potentials, and short-term plasticity in human epilepticneocortex. J Neurosci Res. 2005; 80: 715-264-

3. Welty TE. Juvenile myoclonic epilepsy: epidemiology, pathophysiology, and management. Paediatr Drugs. 2006;8:303-310.

4. Ottman R, Lipton RB Comorbidity of migraine andepilepsy. Neurology.1994; 44(11):2105-2110

5. Yankovsky AE, Andermann F, Bernasconi A Characteristicsof headache associated with intractable partial epilepsy.2005

6. Headache Classification Subcommittee of the InternationalHeadache Society The international classification of headachedisorders,; 2nd edn. Cephalalgia 24(Suppl 1). 2004;1-160.

7. Swartz BE, Simpkins F, Halgren E, et al. Visual working memory in primary generalized epilepsy: an 18FDGPET study. Neurology 1996;47:1203-12.

8. Aminoff, Roger P. Simon, David A. Greenberg, Michael J. Clinicalneurology (7 ed.). New York, N.Y: Lange Medical Books/McGraw Hill. 2009; 85-88.

Andermann E, Andermann FA. Migraine-epilepsy relationships:epidemiological and genetic aspects. In: Andermann F, Lugaresi E, editors. Migraine and epilepsy. Boston: Butterworth. 1987; p. 281-91.

9. De Simone R, Ranieri A et al. Migraine and epilepsy: clinical and pathophysiological relations. Neurol Sci. 2007; (28): 150-55.

10. Samuel F. Berkovic and Douglas E. Crompton. The borderland of epilepsy: A clinical and molecular view, 100 years on. Epilepsia. 2010;51(1): 3-4

11. Strug LJ, Pal DK. Evidence of shared genetic risk factorsfor migraine and Rolandic epilepsy. Epilepsia. 2009; 50(11): 2428-33.

12. Binchin MM, Londero RG, et al. Migraine and epilepsy:A Focus on overlapping Clinical, Pathophysiological, Molecularand Therapeutics Aspects. Current pain and headache reports. 2010; 14(4): 276-83.

13. B. Baykan, I. E. Mart'nez-Juarez, E. A. Altindag, C. S. Camfield,' and P. R. Camfield, "Lifetime prognosis of juvenile myoclonic epilepsy," Epilepsy and Behavior.;vol. 28, supplement 1, pp.2013; S18-S24

14. Toldo I, Perissinotto E, Menegazzo F, Boniver C, Sartori S, Salviati L, Clementi M, Montagna P, Battistella PA

15. Comorbidity between headache and epilepsy in a pediatric headache center. J Headache Pain.2010; 11:235-240

16. Syvertsen M, Helde G, Stovner LJ, Brodtkorb E Headaches add to the burden of epilepsy. J Headache Pain. 2007; 8(4): 224-230

17. Christoph J. Schankin •Jan Re'mi •Ira Klaus •Petra Sostak •Veronika M. Reinisch Soheyl Noachtar •Andreas Straube Headache in juvenile myoclonic epilepsyJ Headache Pain.2011; 12:227-233

18. Sjaastad O, Bakketeig L Tension-type headache: comparisonwith migraine without aura and cervicogenic headache. The VAGA study of headache epidemiology. Funct Neurol23 2008;(2):71-76

19. Jensen R, Stovner LJ Epidemiology and comorbidity ofheadache. Lancet Neurol.2008; 7(4):354-361.

20. Lipton R B, Stewart W F, Diamond S, Diamond M, ReedML. Prevalence and burden of migraine in the United States: results from the American Migraine Study II. Headache. 2001; 41: 646-57.

21. Rasmussen B K, Jensen R, Schrol ML, et al. Epidemiology of headache in a general population: a prevalence study. J Clin Epidemiol. 1991; 44: 1147-57

22. Ito M, Nakamura F, Honma H, Takeda Y, Kobayashi R, Miyamoto T, et al. Clinical factors associated with postictal hea dache in patients with epilepsy. Acta Neurol Scand. 2000; 102: 129-13.

23. Sanchez del Rio M, Bakker D, Wu O, et al. Perfusion- weighted imaging during migraine: spontaneous visual aura and headache. Cephalalgia. 1999; 19(8): 701-7.

24. Bower SM, Aurora KS, Oran JE, at al. Magnetoencephalographicfields from patients with spontaneous and induced migraine aura. Ann Neurol Pain. 2001; 89: 107-10.

25. Liu AW, Delgado-Escueta AV, Gee MN, Serratosa JM, Zhang QW, Alonso ME, Medina MT, Cordova S, Zhao HZ, Spellman JM, Donnadieu FR, Peek JR, Treiman LJ, Sparkes RS. Juvenile myoclonic epilepsy in chromosome 6p12-p11: locus heterogeneity and recombinations. Am J Med Genet 1996; 63(3): 438-446.

26. Hatem Anwar Elmassry, Nahla Nagy, Noha Samy and Maissa Eid Cross section comparative study for comorbid migraine and major depression in epileptic patients: demographic, clinical, electroencahpalograhy and therapeutic implications, Neuropsychiatric Electrophysiology.2015;1:8.

27. Anderson, J., Hamandi, K. Understanding juvenile myoclonic epilepsy:contributions from neuroimaging. Epilepsy Res.2011; 94, 127-137. 
28. De Araujo Filho, G.M., Lin, K., Lin, J., Peruchi, M.M., Caboclo, L.O., Guaranha, M.S.,Guilhoto, L.M., Carrete Jr., H., Yacubian, E.M.,. Are personality traits ofjuvenile myoclonic epilepsy related to frontal lobe dysfunctions? A protonMRS study. Epilepsia 2009;50, 1201-1209.

29. Piazzini, A., Turner, K., Vignoli, A., Canger, R., Canevini, M.P.,. Frontal cognitivedysfunction in juvenile myoclonic epilepsy. Epilepsia.2008; 49, 657-662.

30. Sarchielli P, Tarducci R, Presciutti O, Gobbi G, Pelliccioli GP, Stipa G, et al. Functional 1H-MRS findings in migraine patients with and without aura assessed interictally. Neuroimage 2005; 24: 1025-1031. 